\title{
Fluoride varnish may improve white spot lesions
}

\author{
Abstracted from \\ Du M, Cheng N, Tai B, Jiang H, Li J, Bian Z. \\ Randomized controlled trial on fluoride varnish application for treatment of white spot \\ lesion after fixed orthodontic treatment. \\ Clin Oral Investig 2011; Feb 18. [Epub ahead of print] \\ Address for correspondence: Du.M Department of Preventive Dentistry, \\ School \& Hospital of Stomatology, Wuhan University, 237 Luoyu Road, Wuhan, China, 430079. \\ E-mail: minquandu@163.com
}

\section{Question: Is fluoride varnish effective in reverting white spot lesions (WSLs) after fixed orthodontic treatment?}

Design A randomised, parallel-group, controlled clinical trial. Intervention The test group had fluoride varnish applied onto the tooth surfaces with WSLs using a miniature cotton swab or brush and advised not to brush for four hours. The control group had saline solution applied.

Outcome measure Status of the WSLs were assessed using a DIAGNOdent pen (KaVo, Biberach, Germany).

Results Of the 110 participants recruited, 14 dropped out between the debonding and the six-month recall visit. There were statistically significant differences between the mean DIAGNOdent readings of the two groups at the three-month $(P<0.05)$ and at the six-month followup visits $(\mathrm{P}<0.01)$. No adverse response or safety concerns in the use of fluoride varnish were reported by any of the subjects.

Conclusions A greater decrease in DIAGNOdent pen readings was found in the test group during the first six months after debonding. This may be taken to imply an improvement in the WSLs. Thus, topical fluoride varnish application appears to be a good method to treat WSLs and should be advocated as a routine measure after orthodontic treatment.

\section{Commentary}

The authors' rationale for conducting this study was that while there have been numerous clinical trials evaluating white spot lesions (WSLs) during orthodontic treatment, there is very little information on the use of fluoride treatment for WSLs after orthodontic therapy. A 2004 Cochrane Review, whose focus was on randomised controlled trials in the prevention of WSLs with the use of fluoride during orthodontic treatment, is one of the most noteworthy sources of information on this topic. This Cochrane Review concluded that while the evidence at the time was not strong, patients undergoing orthodontic therapy would benefit from a daily $0.05 \%$ sodium fluoride mouth rinse. They also concluded that higher quality clinical based research was needed in the use of alternative methods of fluoride delivery. ${ }^{1}$

The aim of the study reviewed for this commentary was to evaluate one such alternative method, topical fluoride varnish, and its ability to revert white spot lesions (WSLs) after the debonding of orthodontic brackets. It has been shown that orthodontic patients have a significantly higher incidence of WSLs than patients who have not had orthodontic therapy, ${ }^{2}$ and more recent investigations have put the incidence of WSLs during orthodontic treatment with fixed appliances at $73 \%$ to $95 \% .3$

Topical fluoride varnish has been demonstrated to reduce WSLS during orthodontic treatment, ${ }^{5}$ so one could logically assume that the same effect could be achieved following orthodontic therapy. The purpose of this study was to discover whether or not topical fluoride varnish, when applied in those patients who have WSLs evident following debonding, would be a successful intervention and a preferential method of fluoride delivery. As a delivery mechanism, fluoride varnish applied topically, addresses the issue of patient compliance better than any other current application method and can be applied by auxiliary personnel during routine appointments. ${ }^{6}$

The authors' study design was one in which 12- to 22-year old children, adolescents and young adults were blindly randomised to receive topical fluoride varnish or a placebo (saline) during the first six months following debonding. A unique aspect of this randomised, parallel group, controlled clinical trial was that the WSLs were evaluated by the use of laser fluorescence (Diagnodent Pen ${ }^{\circledR}$, KaVo, Inc.), which has been shown to have a high degree of reliability and validity at quantification of smooth surface lesions. ${ }^{7,8}$ Even though this method of evaluation has been shown to be adversely influenced by a number of variables in the oral environment, ${ }^{8}$ care was taken by the researchers to minimise these 
variables prior to the scans. Baseline readings were taken at the debonding visit and further readings were taken at three and six month intervals. A major strength of this study was that all assessments were carried out by the same evaluator who was blinded as to the subject's group allocation, while other studies have relied strictly on photographic interpretation for inter-observer agreement on WSL progression or regression. ${ }^{5}$

The results showed that there was no statistically significant difference in the intervention group between the third and sixth month, and even though this might indicate that lesion regression had capped at the three-month mark, it would be difficult to draw the conclusion that the WSLs were effectively reversed and that one should halt the administration of topical fluoride varnish at this point. While the authors do suggest that there should be a continuation of professional fluoride varnish application during the first six months following debonding, to their credit, they do mention that longer observation is needed to confirm whether or not the greater change in WSLs is maintained over time. Even with the safety of topical fluoride varnish being well documented, without studies that are longer in term and which were to utilise a larger sample size, it would be difficult to support the six-month timeframe as the de facto standard of care following the debonding of orthodontic brackets.

To summarise, the authors conclusions were not only reasonable but their results add to the existing body of evidence supporting the use of topical fluoride varnish as an effective way of managing WSLs. However, further research is needed to detail more specifics in terms of the duration of topical fluoride varnish application following orthodontic debonding. Their technique also provides the clinician with a practical way to monitor and manage a White Spot Lesion's progression or regression after the debonding of orthodontic brackets.

\section{Practice points}

- Topical fluoride varnish is a safe, effective method of remineralising tooth structure, and as a delivery mechanism it readily addresses the issue of patient compliance better than almost any other method of fluoride application, and can be applied by auxiliary personnel during routine follow-up appointments.

- The use of laser fluorescence (Diagnodent Pen ${ }^{\circledR}, \mathrm{KaVo}_{\mathrm{O}}$ Inc.) can be a practical way to monitor a White Spot Lesion's progression or regression following the debonding of Orthodontic brackets.

Gary L. Stafford

Department of General Dental Sciences, Marquette University School of Dentistry, Milwaukee, Wisconsin, USA.

1. Benson PE, Parkin N, Millett DT, Dyer FE, Vine S, Shah A. Fluorides for the prevention of white spots on teeth during fixed brace treatment. Cochrane Database Syst Rev. 2004; (3): CD003809. Review.

2. Ogaard B, Rølla G, Arends I, ten Cate JM. Orthodontic appliances and enamel demineralization. Part 2. Prevention and treatment of lesions. Am / Orthod Dentofacial Orthop 1988; 94: 123-128.

3. Richter AE, Arruda AO, Peters MC, Sohn W. Incidence of caries lesions among patients treated with comprehensive orthodontics. Am J Orthod Dentofacial Orthop 2011; 139: 657-664.

4. Lovrov S, Hertrich K, Hirschfelder U. Enamel demineralization during fixed orthodontic treatment - incidence and correlation to various oral-hygiene parameters. J Orofac Orthop 2007; 68: 353-363.

5. Stecksén-Blicks C, Renfors G, Oscarson ND, Bergstrand F, Twetman S. Cariespreventive effectiveness of a fluoride varnish: a randomized controlled trial in adolescents with fixed orthodontic appliances. Caries Res 2007; 41: 455-459.

6. Behnan SM, Arruda AO, González-Cabezas C, Sohn W, Peters MC. In-vitro evaluation of various treatments to prevent demineralization next to orthodontic brackets. Am / Orthod Dentofacial Orthop 2010; 138: 712.e1-7; discussion 712-3.

7. De Benedetto MS, Morais CC, Novaes TF, de Almeida Rodrigues ], Braga MM, Mendes FM. Comparing the reliability of a new fluorescence camera with conventional laser fluorescence devices in detecting caries lesions in occlusal and smooth surfaces of primary teeth. Lasers Med Sci 2011; 26: 157-162.

8. Aljehani $A$, Yang $L$, Shi XQ. In vitro quantification of smooth surface caries with DIAGNOdent and the DIAGNOdent pen. Acta Odontol Scand 2007; 65: 60-63.

Evidence-Based Dentistry (2011) 12, 104-105. doi:10.1038/sj.ebd.6400823 